Rafeya Sohail and Nazia Jamil*

\title{
Isolation of biosurfactant producing bacteria from Potwar oil fields: Effect of non-fossil fuel based carbon sources
}

https://doi.org/10.1515/gps-2020-0009

Received March 30, 2019; accepted September 04, 2019.

Abstract: Biosurfactants are surface-active metabolites produced by microorganisms. Biosurfactants tend to solubilize hydrocarbons in the surrounding environment, by reducing surface tension and increasing carbon uptake. In this study, isolation of biosurfactant producing bacteria and effect of renewable, non-fossil fuel based carbon sources on production were assessed. Oil field produced water was collected from Potwar oil fields and thirteen strains were isolated. Strains were screened for biosurfactant production by hemolysis test, emulsification index test, emulsification assay, oil displacement test, drop collapse test, tilted glass slide test and oil coated agar emulsification test. Strains were further screened for maximum production on cost effective renewable carbon source e.g. glucose, waste glycerol and animal fat. Promising strains were identified as Bacillus subtilis (MH142143), Pseudomonas aeruginosa (MH142144), Bacillus tequilensis (MH142145) and Bacillus safensis (MH142146) by $16 \mathrm{~S}$ rRNA gene sequencing. Among all isolates, highest biosurfactant production on glucose (37\%), glycerol (48\%) and animal fat oil (49\%), after $24 \mathrm{~h}$ cultivation was by Pseudomonas aeruginosa. Biosurfactant showed similarity to rhamnolipids by Thin Layer Chromatography (TLC). Assessment of bioactive propertiaes of rhamnolipid showed strong antimicrobial activity against Bacillus spp. Future investigations can be focused on application of these strains in environmental as well as industrial sectors.

Keywords: animal fat oil; biosurfactant; produced water; Pseudomonas aeruginosa; waste glycerol

\section{List of abbreviations \\ BS Biosurfactant \\ LA Luria Agar}

\footnotetext{
* Corresponding author: Nazia Jamil, Department of Microbiology and Molecular Genetics, University of the Punjab, Lahore 54590, Pakistan, e-mail: nazia.mmg@pu.edu.pk

Rafeya Sohail, Department of Microbiology and Molecular Genetics, University of the Punjab, Lahore 54590, Pakistan
}

$\begin{array}{ll}\text { LB } & \text { Luria Broth } \\ \text { MEGA } & \text { Molecular Evolutionary Genetics Analysis } \\ \text { MSM } & \text { Mineral Salt Media } \\ \text { PW } & \text { Produced water } \\ \text { RL } & \text { Rhamnolipid } \\ \text { TLC } & \text { Thin Layer Chromatography }\end{array}$

\section{Introduction}

Nowadays, use of petroleum and petroleum base polymers has increased to an alarming degree. These polymers facilitate us in many different ways but their accumulation, non-biodegradability and contamination has been a concern - voiced by many. Oil fields contain large quantities of produced water, as it is the largest by-product associated with oil and gas exploration [1]. Oil field produced water contain large quantities of hydrocarbons especially petroleum, diesel oils, many aromatic compounds, dispersed oil and radionuclides [2]. Certain indigenous hydrocarbon degrading microorganisms - able to use these toxic metabolic wastes in a bioremediation process to help their own survival - are present in produced water. Hydrocarbon degrading bacteria are found to be most active among these. Biosurfactants (BS) are heterogeneous amphiphilic surface-active compounds that reduce surface and interfacial tension [3]. Biosurfactants help the cell survival and promote growth kinetics by reduction of surface tension and facilitation of uptake of hydrocarbon by hydrocarbon solubilization [4]. Biosurfactant producers are a group of hydrocarbon degraders, which show high surface activity and aid in degradation of harmful metabolites. Surface activity of biosurfactants helps in formation of microemulsions in which hydrocarbon solubilization can occur [5]. Bacteria belonging to genera Pseudomonas, Bacillus, Corynebacterium, Klebsiella, Acinetobacter, Archromobacter, Falvobacterium and Proteobacteria have been reported to produce efficient biosurfactants [6]. Most biosurfactants, known to date, are produced on immiscible hydrocarbons but some are produced on miscible hydrocarbons [5]. Biosurfactants 
consist of hydrophilic and hydrophobic moieties. Hydrophilic moieties help in reduction of surface tension levels, promotion of hydrocarbon desorption and solubilization. Hydrophobic moieties are concerned with the relationship between interface of surfactant molecules and liquid droplets [7].

Biosurfactants can be classified as low molecular weight biosurfactants; dealing mainly with the reduction in surface and interfacial tension levels, and high molecular weight biosurfactants; dealing mainly with emulsification and stabilization $[8,9]$. The chemical composition of biosurfactants depends on the biosynthetic pathway and enzymes (mainly transferases and synthases) needed for their production. Based on chemical composition, biosurfactants have been classified as glycolipids, lipopeptides, phospholipids, and neutral lipids. There are also polymeric biosurfactants e.g. emulsions, biodispersan, etc. [10]. Sophorolipids, rhamnolipids, lipomanan, surfactin, emulsan, iturin, liposen, lichenysin, alasan etc. are some of the best studied biosurfactants [11]. Two most common bacterial biosurfactants are rhamnolipids (produced by Pseudomonas aeruginosa), and surfactins (produced by Bacillus subtilis) [10]. Out of all these classes, glycolipids, mainly rhamnolipids are most thoroughly studied. Importance of rhamnolipids is, in part, due to their high bioactivity and antimicrobial properties. Production and synthesis of biosurfactants is susceptible to many external factors including $\mathrm{pH}$, temperature, carbon, and nitrogen sources etc. Maximum growth was observed using glucose at $37^{\circ} \mathrm{C}$ and $\mathrm{pH} 7$ [10]. RhlA enzyme is involved in initiating rhamnolipid biosynthesis [12]. rhlC and $r h l B$ genes encodes the enzyme needed for synthesis of rhamnolipids [13]. Gene $r m l A, r m l B, r m l C$, and $r m l D$ are needed for the synthesis of rhamnose skeleton.

Recent advancements have provided the information that biosurfactants are a vital part of growth and reproduction of most biosurfactant producers e.g. Bacillus needs surfactin (biosurfactant) for formation of fruiting body, needed in order to reproduce [9]. Few biosurfactants adhere to cell membrane but most are released into the extracellular environment where these aid in cell survival through various biophysicochemical routes. Biosurfactants are set apart from their synthetic counterparts because of their biodegradable nature, low toxic levels, low irritancy, specific selectivity for human skin cells, effectiveness as well as ease of synthesis and extraction [5]. Although, most significant use of biosurfactants, to date, has been in petroleum and biodiesel industries pertaining to clearing oil spills, enhancing oil quality and removal of sludge from oil tanks, biosurfactants also have multifarious applications in the field of environmental sciences. These biosurfactants, due to their hydrocarbon degradation capability and biodegradative nature, have high potential for ecofriendly bioremediation of oil-contaminated sites, heavy metal pollution and pesticides, washing and cleaning of oil reservoirs etc. [14]. This property of biosurfactants can also be employed for management of wastewater pollution [10]. Emulsification and surface active properties of biosurfactants have made their use as detergents, foaming and wetting agents, flocculants, etc. possible [15]. Due to their high compatibility with human skin, most cosmetic industries employs biosurfactants in shampoos, tooth pastes and other products [4]. Food industries are also employing biosurfactants, as these tend to raise the quality of fat-based products [9]. Some biosurfactants display therapeutic and antimicrobial properties. Biosurfactants are used as biocontrol, for plant disease protection, due to their microbicidal effect [6]. Rhamnolipids possess strong antifungal properties. Rhamnolipids also serve to reduce metal toxicity [10].

Presence of biosurfactant producers in produced water samples collected from oil fields of Potwar, Pakistan was assessed. Bacterial flora of PW was screened for biosurfactant production by different qualitative and quantitative tests. Isolated strains were screened for biosurfactant production by hemolysis test, for which 31\% isolates tested positive. These hemolytic strains were further screened using criteria such as emulsification index test, emulsification assay, oil displacement test, drop collapse test, tilted glass slide test and by using oil coated agar emulsification test. The effect of carbon sources - glucose, glycerol, and animal fat - on biosurfactant production was also evaluated. Biosurfactant samples were analyzed using thin layer chromatography (TLC).

\section{Materials and methods}

\subsection{Sample collection and isolation of bacterial strains}

Potwar oil fields have tons of waste produced water, which was collected in sterile bottle and stored at $4^{\circ} \mathrm{C}$. Sample was characterized by measuring $\mathrm{pH}$, temperature, color, texture, and smell of sample. Dilutions of sample were prepared by serial dilution method. Dilutions $10^{\circ}, 10^{-1}$ and $10^{-2}$ were aseptically transferred to Luria Agar plates by spread plate method. Plates were incubated at $37^{\circ} \mathrm{C}$ for $24 \mathrm{~h}$. Colonies with distinguishing morphological features were restreaked two to three times to obtain pure culture. Microscopy was used for identification and differentiation 
of isolated strains. Gram, spore, and capsule staining techniques were employed. Biochemical properties of isolates were determined by employing different qualitative tests such as catalase activity test, oxidase test, DNase test, starch hydrolysis test, citrate utilization test, motility test and urease activity test etc. [16].

\subsection{Screening of biosurfactant (BS) producers}

Isolated strains were screened for by hemolysis test for direct screening. Ability of strains to produce biosurfactant was further analyzed by emulsification index, emulsification assay, oil displacement, drop collapse, tilted glass slide tests and by using oil coated agar plates [10,17-21].

\subsubsection{Hemolytic activity}

Blood agar media containing 5\% v/v human blood was streaked with isolated strains and incubated at $37^{\circ} \mathrm{C}$ for $24 \mathrm{~h}$. After incubation, zone formation around culture was observed. Hemolytic activity is qualitative indication of biosurfactant production [17].

\subsubsection{Emulsification assay}

Strains were cultivated on MSM at $37^{\circ} \mathrm{C}$ for $24 \mathrm{~h}$. Culture broth was centrifuged at $6000 \mathrm{rpm}$ for $15 \mathrm{~min}$ and cell free supernatant was obtained. $3 \mathrm{~mL}$ of supernatant was mixed with $0.5 \mathrm{~mL}$ oil, vortexed for $2 \mathrm{~min}$ and then left undisturbed for $1 \mathrm{~h}$. Absorption of aqueous phase was measured at $400 \mathrm{~nm}[17,18]$. Emulsification activity per $\mathrm{mL}(\mathrm{EU} / \mathrm{mL})$ was calculated as product of absorbance and dilution factor.

\subsubsection{Emulsification index test}

$2 \mathrm{~mL}$ of volume of supernatant and oil were mixed vigorously for $2 \mathrm{~min}$ and then left undisturbed for $24 \mathrm{~h}$. After $24 \mathrm{~h}$, height of emulsified layer and total height of mixture was observed [17,19]. Emulsification index was calculated as follows:

$$
\text { Emulsification Index (E24) }=\frac{\begin{array}{c}
\text { Height of } \\
\text { emulsified layer }
\end{array}}{\text { Total height }} \times 100
$$

\subsubsection{Oil spreading assay}

$40 \mathrm{~mL}$ of distilled water was taken in clean glass petri plates. $20 \mu \mathrm{L}$ oil and $10 \mu \mathrm{L}$ cell free supernatant was added. System was monitored carefully for formation of halo around supernatant, indicative of positive test result $[10,20]$.

\subsubsection{Drop collapse assay}

A single droplet of oil and supernatant was taken on a clean glass slide. Droplet of supernatant was monitored carefully to notice whether it remained beaded or collapsed [20,21]. Collapsed supernatant drop was scored as positive “+," indicative of biosurfactant presence.

\subsubsection{Tilted glass slide assay}

A single droplet of $0.9 \% \mathrm{NaCl}$ was taken on a clean glass slide angled at 45 degrees and a single colony of isolated was transferred to it. Colony was not mixed in $0.9 \% \mathrm{NaCl}$ droplet. Droplet was monitored carefully to observe whether it remained beaded or collapsed $[17,18]$. Beaded drop was scored as negative “-," indicative of biosurfactant absence.

\subsubsection{Oil coated agar plate test}

Surface of Nutrient agar media plates were coated with oil. Plates were streaked with isolated strains and incubated at $37^{\circ} \mathrm{C}$ for 7 days. Plates were observed for presence of emulsification halo around culture growth, indicative of biosurfactant activity [22].

\subsection{Molecular analysis}

Strains were cultivated on Nutrient agar slants and genomic DNA was isolated by rapid DNA isolation method. 16S rRNA sequencing of promising strains was done by Sanger dideoxy sequencing [23]. Reverse primer sequence was converted to complementary sequence and assembled with forward sequences, to obtain consensus sequences, using Chromas Pro 2.6.5 [24] and Cap3 [25], respectively. Sequences were inspected for maximum homology against GenBank using BlastN [26]. Sequences were submitted to GenBank. Evolutionary 
relationships of promising strains were mapped using MEGA4 to construct phylogenetic trees by neighbor joining method [27].

\subsection{Optimization of biosurfactant production}

Mineral salts media (MSM) used, in this study, a modification of mineral salts solution developed by Knetting and Zajic [5] . Promising strains were cultivated on MSM supplemented separately with glucose, waste glycerol, and animal fat oil [28]. Animal fat oil was extracted by heating animal fat and decanting the residue. Extracted oil was filtered to remove any impurities. Each carbon source was used in $2 \% \mathrm{v} / \mathrm{v}$ concentration in one liter of mineral salt media. Biosurfactant productions were conducted in $500 \mathrm{~mL}$ flasks of $300 \mathrm{~mL}$ MSM supplemented with $2 \%$ carbon source. Media was incubated at $37^{\circ} \mathrm{C}$ for $96 \mathrm{~h}$. Growth kinetics of promising biosurfactant producers were observed by measuring culture density at $600 \mathrm{~nm}$ at regular intervals [29]. Dry weight of biomass and biosurfactant was recorded over a period of $96 \mathrm{~h}$ using dry weight method [30]. Biomass and biosurfactant are mean of values recorded during production kinetics. Standard error of each value was calculated.

\subsection{Biosurfactant (BS) extraction}

Culture broth was collected and centrifuged to obtain cell free supernatant containing biosurfactant. Supernatant was treated with $\mathrm{HCl}$ to obtain $\mathrm{pH} 2$ and then left undisturbed overnight at $4^{\circ} \mathrm{C}$. Supernatant was centrifuged at $10,000 \mathrm{rpm}$ at $4^{\circ} \mathrm{C}$ to separate out acid precipitated biosurfactant (pellet). Crude biosurfactant was treated with methanol: chloroform (1:2) and centrifuged again to obtain purified biosurfactant precipitate $[5,10,19]$. Pure biosurfactant was dried and stored in phosphate buffer. Percentage biosurfactant was calculated by using the formula (Eq. 2):

$\%$ Biosurfactant $=\frac{\text { weight of biosurfactant }}{\text { weight of biomass }} \times 100$

\subsection{Thin layer chromatography (TLC)}

Biosurfactant samples of strains were extracted and analyzed by TLC. Polysorbate 80 was taken as control.
TLC plates were developed in a solvent system of chloroform: methanol (65:7). Developed plates were visualized under UV at longer and shorter wave lengths and then subjected to iodine fumes for detection of lipids $[5,10,31]$.

\subsection{Antimicrobial activity}

Rhamnolipid sample of Pseudomonas aeruginosa was analyzed for antibacterial activity by preparing rhamnolipid discs and placing discs on culture lawn of Bacillus subtilis and Pseudomonas aeruginosa. Dilution of ampicillin was taken as negative control. Zone formation around rhamnolipid discs is an indication of antimicrobial activity [32].

\section{Results}

\subsection{Sample collection and isolation of bacterial strains}

Produced water sample was observed to have an oily texture with a diesel smell and brown color. Temperature of sample was measured as $27^{\circ} \mathrm{C}$ while $\mathrm{pH}$ was recorded as 6.0. Thirteen discrete colonies were selected from mixed culture plates of sample dilutions $10^{0}, 10^{-1}, 10^{-2}$ and labelled as (produced water strains) PWA to PWM. Microscopic measurements of bacterial cells were recorded after observation under light microscope. Out of thirteen isolates, eleven were gram-positive rods, while one was gram-positive cocci and one was gramnegative rods. Seven strains were spore-formers and capsulated, DNase positive and motile. Nine strains were catalase positive and utilized citrate. Eleven strains were oxidase positive. Three were urease positive. Ten strains hydrolyzed starch. Staining results and biochemical characterization of strains indicated that most isolates belong to genus Pseudomonas, Bacillus and Rhodococcus.

\subsection{Screening of biosurfactant (BS) producers}

On screening for biosurfactant production, only strains that gave positive result for all tests were selected as producers i.e. PWA, PWC, PWF, and PWG. PWC, PWF, and PWG showed $\beta$-hemolysis while PWA showed $\alpha$-hemolysis. 
Emulsification index (EI) of PWA was highest (21.72), while that of PWG was lowest (7.81). Emulsification assay $(\mathrm{EI} / \mathrm{mL})$ of PWC was highest (125.0) while that of PWG was lowest (87.6). On oil spreading assay, PWA had largest halo diameter $(0.42 \mathrm{~cm})$, while PWC had smallest diameter $(0.14 \mathrm{~cm})$. On oil coated agar plate assay, these four strains showed oil emulsification around culture growth. On drop collapse assay and tilted glass slide assay, supernatant drops of these strains collapsed while others remained in beaded form (Table 1).

\subsection{Molecular analysis}

16S rRNA genes of promising strains PWA, PWC, PWF, and PWG were sequenced and strains were identified as Bacillus subtilis (MH142143), Pseudomonas aeruginosa (MH142144), Bacillus tequilensis (MH142145) and Bacillus safensis (MH142146) respectively. Prime biosurfactant producing strain among these four strains was PWC. Evolutionary relationships of strains PWA, PWC (Figure 1), PWF, and PWG were mapped by neighbor joining method using MEGA4.

\subsection{Kinetics of biosurfactant (BS) production}

Production kinetics were mapped for all four biosurfactant producers. Over a period of $96 \mathrm{~h}$, all strains gave high biomass and biosurfactant productions on all carbon sources. Biomass of Bacillus subtilis increased exponentially after $24 \mathrm{~h}$. After $24 \mathrm{~h}$, biosurfactant production on animal fat oil was 39\%. After $96 \mathrm{~h}$, highest biosurfactant production (36\%) was also on animal fat oil. Lowest biosurfactant production (31\%) was on glycerol. In case of Pseudomonas aeruginosa, highest biomass was obtained on glucose but largest quantity of biosurfactant was produced on animal fat oil. Results depicted in Figure 2, show the biomass and biosurfactant production by Pseudomonas aeruginosa on Mineral salt media containing glucose, glycerol and animal fat oil. Maximum biomass production was obtained after $96 \mathrm{~h}(110.4 \mathrm{~g} / \mathrm{L})$ on using glucose as sole carbon source. Biosurfactant obtained after $24 \mathrm{~h}$ (49\%) was highest using animal fat oil. Shift in biosurfactant concentration, after initial build up, was also noted in case of animal fat oil after $96 \mathrm{~h}$ (35\%).

In case of Bacillus tequilensis, highest biomass (117.8 $\mathrm{g} / \mathrm{L})$, and biosurfactant production (30\%) after

Table 1: Screening for biosurfactant producers.

\begin{tabular}{lccccccc}
\hline Strains & $\begin{array}{c}\text { Hemolytic } \\
\text { activity }\end{array}$ & $\begin{array}{c}\text { Emulsification } \\
\text { index }\left(\mathrm{E}_{24}\right)\end{array}$ & $\begin{array}{c}\text { Emulsification } \\
\text { assay }(\mathrm{El} / \mathrm{mL})\end{array}$ & $\begin{array}{c}\text { Oil spreading } \\
(\mathbf{c m})\end{array}$ & $\begin{array}{c}\text { Oil coated } \\
\text { agar plate }\end{array}$ & $\begin{array}{c}\text { Drop } \\
\text { collapse }\end{array}$ & $\begin{array}{c}\text { Tilted glass } \\
\text { slide }\end{array}$ \\
\hline PWA & + & 21.73 & 92.0 & 0.42 & + & + & + \\
PWC & + & 15.0 & 125.0 & 0.14 & + & + & + \\
PWF & + & 9.61 & 123.6 & 0.27 & + & + & + \\
PWG & + & 7.81 & 87.6 & 0.17 & + & + & + \\
\hline
\end{tabular}

+ (Positive test result) - (Negative test result)

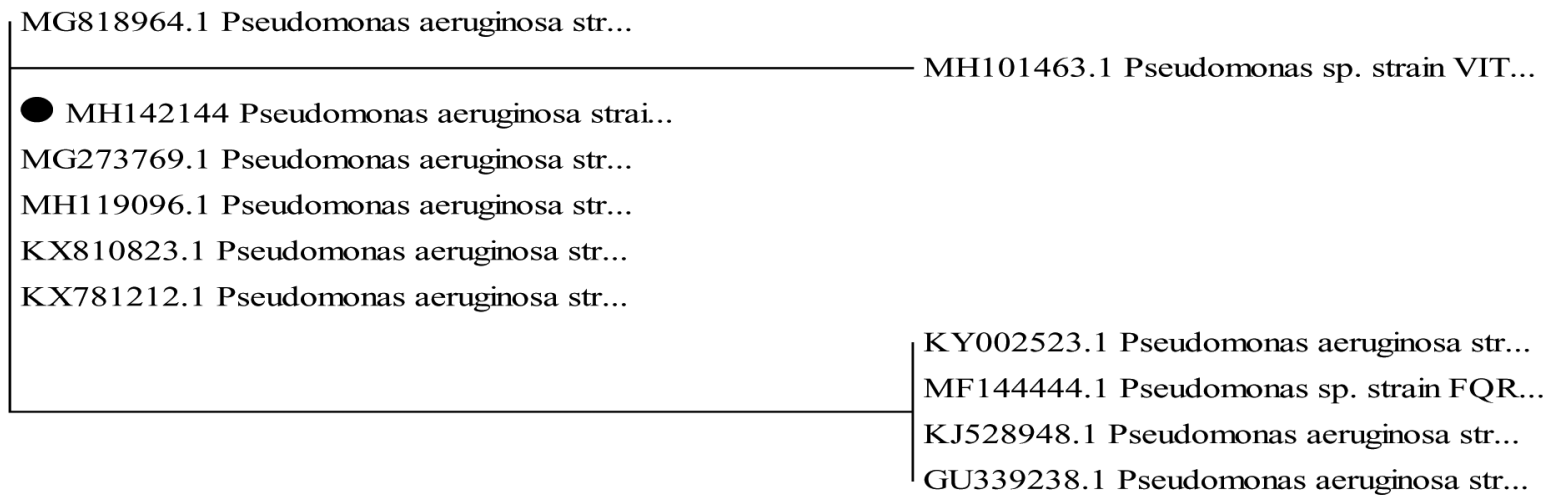

$$
\stackrel{\longrightarrow}{\longrightarrow .00005}
$$

Figure 1: The phylogenetic tree of Pseudomonas aeruginosa; MH142144 (strain PWC) and related strains based on 16S rRNA sequences, was constructed by the neighbor-joining method using MEGA4. Strain PWC (MH142144) is indicated by circle (•). 
$96 \mathrm{~h}$ was on animal fat oil. While, lowest biomass (116.3 g/L) and biosurfactant production (26\%) was on glycerol (Figure 3). Biomass and biosurfactant production by Bacillus safensis increased exponentially up to $96 \mathrm{~h}$. After 96 h, comparatively lower biomass (88.9 g/L) and biosurfactant production (21\%) was on glucose. Whereas, higher biomass $(76.3 \mathrm{~g} / \mathrm{L})$ and highest biosurfactant production (30\%) was on animal fat oil (Figure 4).

\subsection{Biosurfactant analyzation}

Preliminary analysis of biosurfactant sample of Pseudomonas aeruginosa indicated the presence of glycolipids. Preliminary analysis of biosurfactant samples indicated the presence of glycolipids and lipoproteins (Figure 5). Spots on TLC plate developed in chloroform: methanol (65:7) were labelled as V: visible

\section{Biosurfactant production by Pseudomonas aeruginosa}

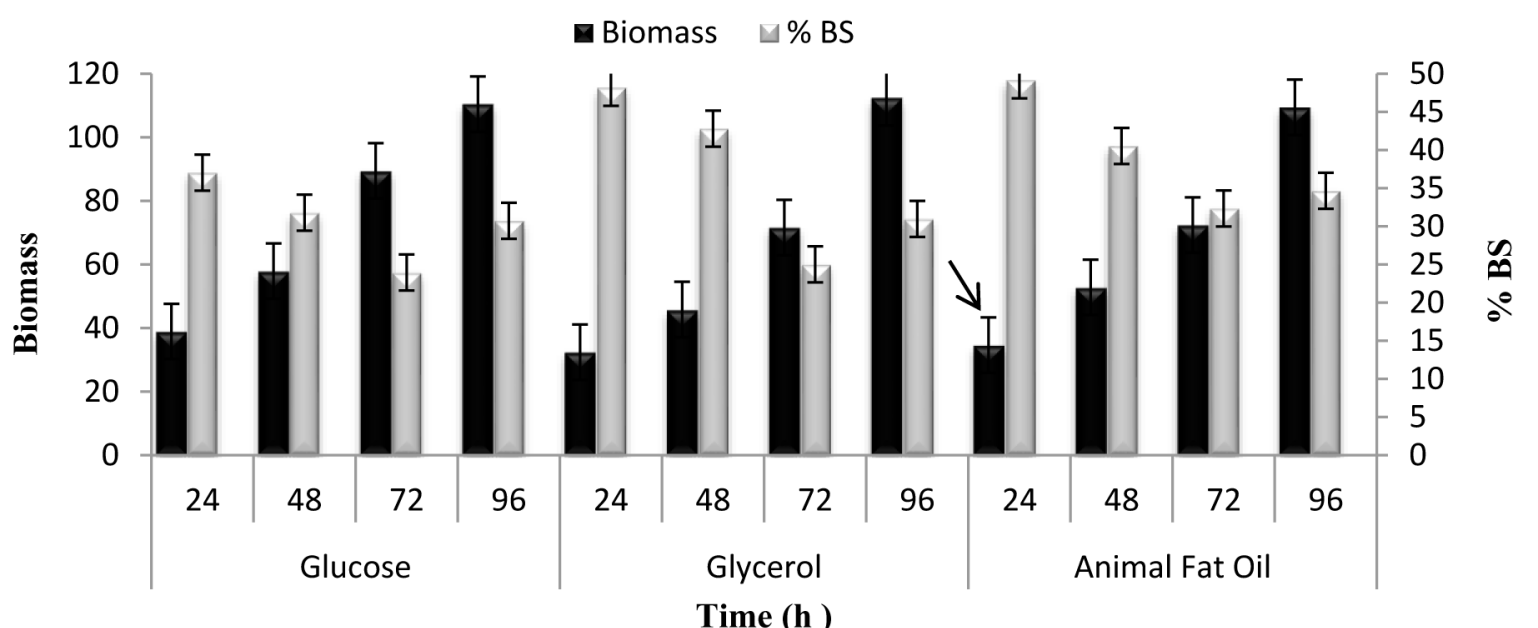

Figure 2: Time profiling for biosurfactant production by strain PWC (Pseudomonas aeruginosa; MH142144) showed high production on all carbon sources. Highest biosurfactant production was on animal fat oil $(17.0 \mathrm{~g} / \mathrm{L})$ while lowest biosurfactant production was on glucose $(14.4 \mathrm{~g} / \mathrm{L})$. Biomasses are the mean of values recorded during production kinetics. Standard error of each value was calculated.

\section{Biosurfactant production by Bacillus tequilensis}

B Biomass $\square \%$ BS

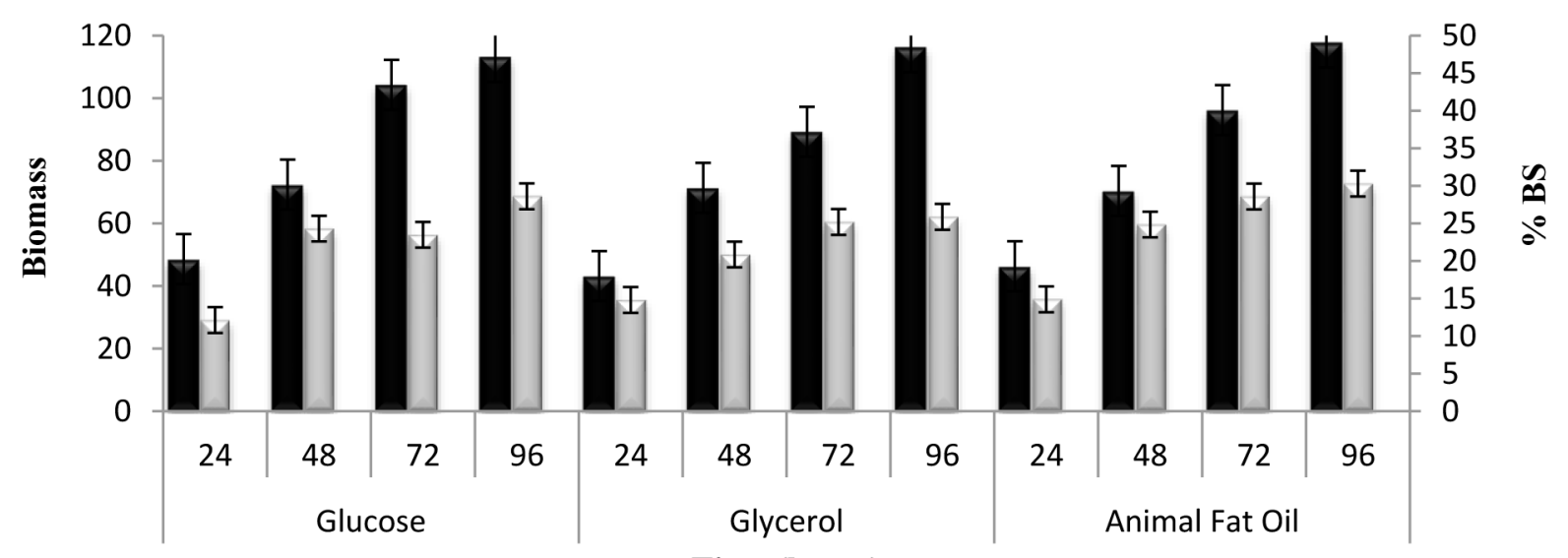

Time (hours)

Figure 3: Time profiling for biosurfactant production by strain PWF (Bacillus tequilensis; MH142145) showed highest production on animal fat oil $(35.7 \mathrm{~g} / \mathrm{L})$ while lowest biosurfactant production was on glycerol $(30.1 \mathrm{~g} / \mathrm{L})$. Biomasses are the mean of values recorded during production kinetics. Standard error of each value was calculated. 


\section{Biosurfactant production by Bacillus safensis}

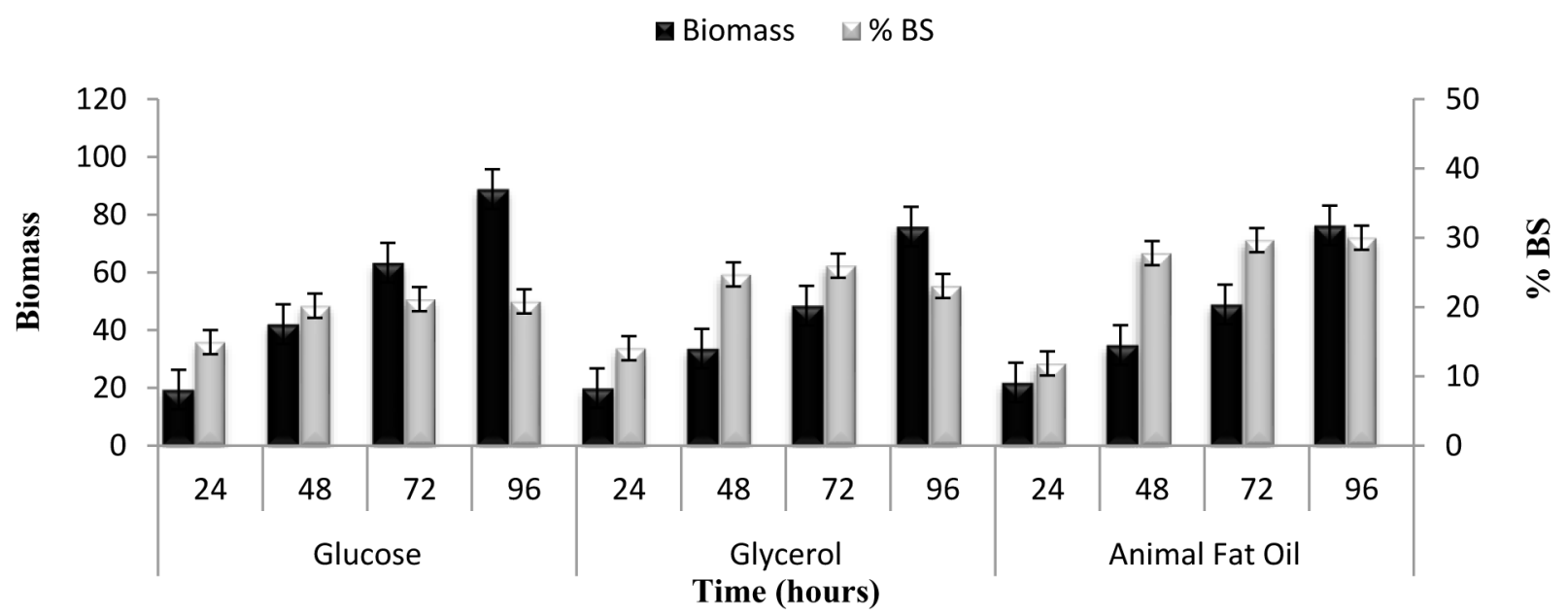

Figure 4: Time profiling for biosurfactant production by strain PWG (Bacillus safensis; MH142146) showed highest production on animal fat oil (22.9 g/L) while lowest biosurfactant production was on glucose $(18.5 \mathrm{~g} / \mathrm{L})$. Biomasses are the mean of values recorded during production kinetics. Standard error of each value was calculated.

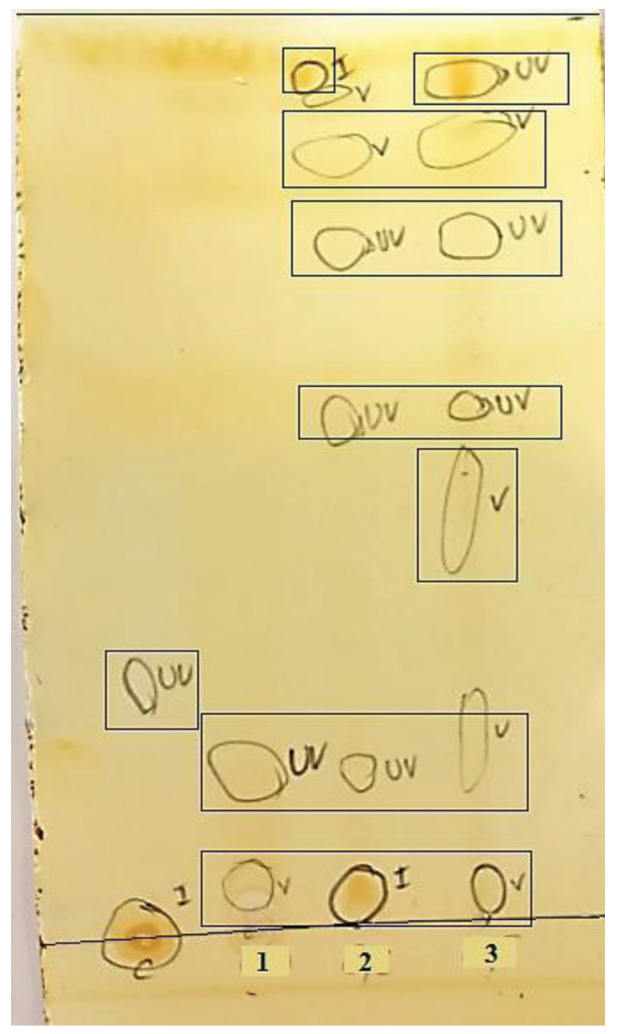

Figure 5: TLC results (C) control, (1) biosurfactant sample of Bacillus safensis, (2) biosurfactant sample of Pseudomonas aeruginosa, (3) biosurfactant sample of Bacillus tequilensis.

with naked eye, UV: visible under UV and I: visible after treatment with iodine fumes. Control (C) showed spots corresponding to diglycerides $(\mathrm{Rf}$ value $=0.32$ )
Biosurfactant samples of Bacillus safensis (1) showed spots corresponding to triglycerides ( $\mathrm{Rf}$ value $=0.12)$ and diglycerides $(\mathrm{Rf}$ value $=0.25)$. Pseudomonas aeruginosa (2) showed spots corresponding to triglycerides $($ Rf value $=0.1)$, diglycerides $($ Rfvalue $=0.24)$, glycolipid; $(\mathrm{Rf}$ value $=0.68)$ and free fatty acids $($ Rf value $=0.76)$. Glycolipid sample of Pseudomonas aeruginosa was indicative of rhamnolipids due to similarity of Rf value [31]. Bacillus tequilensis (3) showed spots corresponding to triglycerides ( $\mathrm{Rf}$ value $=0.1$ ), diglycerides $(\mathrm{Rf}$ value $=0.3)$, sterols $(\mathrm{Rf}$ value $=0.48)$, glycolipid $($ Rf value $=0.69)$ free fatty acids $($ Rf value $=0.78)$ and lipoproteins $(\mathrm{Rf}$ value $=0.82)$. Presence of rhamnolipids was further strengthened by their strong antibacterial activity against Bacillus. Zone of inhibition against Bacillus was $2.0 \mathrm{~cm}$.

\section{Discussion}

One major pollution associated problem of oil fields is produced water whose rich hydrocarbon content of produced water accounts for presence of high number of hydrocarbon degrading microorganisms, including biosurfactant-producing bacteria. Sample enumeration conducted to determine bacterial load present in sample indicated that it was significantly higher than in water. Sample enumeration and subsequent pure culture isolation resulted in isolation of thirteen morphologically different colonies from mixed culture of sample. Out of 
these thirteen, $84.6 \%$ were gram-positive rods whereas gram-positive cocci and gram-negative rods were both $7.69 \%$ each. Cultural and biochemical characterization of these isolated strains aided in further classification of these pure cultures. For screening of biosurfactant production, hemolysis test was employed, as hemolytic activity is considered a clear indication of biosurfactant production by many authors [5]. Emulsification assay, emulsification index and hydrocarbon layered assay test only give an indication of biosurfactant presence, as often these do not correlate with surface activity. Collapse and spreading assay rely on destabilization of droplets, due to reduction in interfacial tension, in the presence of surfactants and surfactant activity respectively [18]. Out of thirteen isolates, 31\% were biosurfactant producers (Table 1).

Present study deals with isolation of biosurfactant producing bacteria and effect of non-fossil fuel based carbon sources on production kinetics. Production kinetics were mapped using glucose, waste glycerol, and animal fat oil [33]. Glucose and related compounds have a large hydrocarbon skeleton and bacteria, which can successfully utilize them, are able to obtain an easily replenishable supply of carbon, as compared to other carbon sources [34]. Waste glycerol is a main byproduct of biodiesel industry. Large quantities of waste glycerol are generated annually. Utilization of glycerol, therefore, imparts an evolutionary and biodegradability advantage to bacteria that can catabolize glycerol into simple components [35]. Many industrial sectors such as meat processing industries, tanneries, oil processing industries, and food industries, etc. produce significant quantities of animal fat, lard, grease, and tallow as waste [36]. This waste animal fat is used considerably less than other industrial wastes and poses a problem for disposal as well as utilization. Using animal fat as substrate for commercial production of biosurfactants etc. resolves this issue [28]. Animal fat was used in this study as an easily replenishable carbon source to obtain a measure of biodegradative activity of isolated strains [37]. Differences in biosurfactant production over the period of $96 \mathrm{~h}$ showed that initially biosurfactant was used up after $24 \mathrm{~h}$, to solubilize hydrocarbons. Biosurfactant quantity was insufficient to form micelles at $48 \mathrm{~h}$, but it started to increase again after $48 \mathrm{~h}$. High biosurfactant production was observed, in case of PWA, Bacillus subtilis. In a similar study, Pereira et al. reported $21.58 \mathrm{~g} / \mathrm{L}$ biosurfactant production by Bacillus subtilis [38]. Strain PWC (Pseudomonas aeruginosa; MH142144) showed highest growth rate on glucose, followed by animal fat oil and lowest growth rate on waste glycerol supplemented media (Figure 2). Biomass also increased exponentially up to $24 \mathrm{~h}$. Fall of biomass relates to stationary phase of growth indicating a regulatory switch to rhamnolipid (RL) synthesis [13]. Biomass of Pseudomonas increased after $24 \mathrm{~h}$ but biosurfactant production decreased after 24 h. Although highest growth was observed when glucose supplemented media was utilized, overall, highest production of biosurfactant was observed when animal fat oil was used. Similar studies were conducted by Nitschke et al. [39] who reported $75 \%$ biosurfactant production by Pseudomonas aeruginosa using oil wastes. Also Robert et al. [29] reported 38.2\% production using olive oil.

PWF, Bacillus tequilensis, showed gradually increasing biosurfactant concentration after $24 \mathrm{~h}$ (Figure 3). Highest biosurfactant production was observed after $96 \mathrm{~h}$. In a similar study, Camargo et al. reported $1.52 \mathrm{~g} \cdot \mathrm{L}^{-1} \cdot \mathrm{h}^{-1} \mathrm{BS}$ production by Bacillus tequilensis, when initial biomass concentration was $0.33 \mathrm{~g} / \mathrm{L}$ [40]. PWG, Bacillus safensis also showed exponential increase in biosurfactant production (Figure 4). In a study on biosurfactant production by Bacillus safensis, Domingo et al. reported high production of biosurfactant resembling pumilacidin [41].

Analysis of TLC spots of biosurfactant samples indicated presence of triglycerides, diglycerides, glycolipid, sterols, free fatty acids, and lipoproteins (Figure 5). Triglycerides and diglycerides spots were observed in case of biosurfactant produced by Bacillus safensis indicating neutral lipids presence. In case of Bacillus tequilensis, lipoprotein spots were observed after treatment with iodine. These spots indicate the reaction of iodine vapors with lipid and protein parts of biosurfactant sample. Similar results were reported by Al-Wahaibi et al. during screening of minimal salt media for biosurfactant production by Bacillus subtilis and Bacillus licheniformis [42]. Further investigation focusing on identification and characterization of the type of biosurfactants are required. Glycolipid spots of Pseudomonas aeruginosa showed TLC spots of Rf value 0.68 , which was assigned to rhamnolipids [31]. Comparable results were reported by Elshikh et al. [32], who studied natural antimicrobial activity of rhamnolipids. According to screening results and production kinetics, strains isolated from Potwar oil fields, Pakistan produced large amounts of biosurfactant, using renewable carbon sources as feedstock. This suggests potential exploitation as a promising resource conserving innovative, for large-scale production and application in environmental sectors.

Acknowledgements: Authors thank Higher Education Commission of Pakistan for the assistance and funding during this study; under the project number NRPU 3443. 


\section{References}

[1] Igunnu E.T., Chen G.Z., Produced water treatment technologies. LCT, 2012, 9(3), 157-177.

[2] Akob D.M., Cozzarelli I.M., Dunlap D.S., Rowan E.L., Lorah M.M., Organic and inorganic composition and microbiology of produced waters from Pennsylvania shale gas wells. Appl. Geochem., 2015, 60, 116-125.

[3] Madsen J.K., Pihl R., Møller A.H., Madsen A.T., Otzen D.E., Andersen K.K., The anionic biosurfactant rhamnolipid does not denature industrial enzymes. Front. Microbiol., 2015, 6(292).

[4] Mahalingam P., Sampath N., Isolation, characterization and identification of bacterial biosurfactant. Eur. J. Exp. Biol., 2014, 4(6), 59-64.

[5] Tabatabaee A., Assadi M.M., Noohi A., Sajadian V., Isolation of biosurfactant producing bacteria from oil reservoirs. J. Environ. Health Sci., 2005, 2(1), 6-12.

[6] Ahmad Z., Arshad M., Asghar H.N., Sheikh M.A., Crowley D.E., Isolation, Screening and Functional Characterization of Biosurfactant Producing Bacteria Isolated from Crude Oil Contaminated Site. Int. J. Agric. Biol., 2016, 18(3).

[7] Pacwa-Ptociniczak M., Ptaza G.A., Piotrowska-Seget Z., Cameotra S.S., Environmental applications of biosurfactants: recent advances. Int. J. Mol. Sci., 2011, 12(1), 633-654.

[8] Bognolo G., Biosurfactants as emulsifying agents for hydrocarbons. Colloid. Surface. A, 1999, 152(1-2), 41-52.

[9] Ebrahimi A., Tashi N., Lotfalian S., Isolation of biosurfactant producing bacteria from oily skin areas of small animals. Jundishapur J. Microb., 2012, 5(2), 401.

[10] Batool R., Ayub S., Akbar I., Isolation of biosurfactant producing bacteria from petroleum contaminated sites and their characterization. Soil Environm., 2017, 36(1), 1-10.

[11] Vijayakumar S., Saravanan V., Biosurfactants-types, sources and applications. Res. J. Microbiol., 2015, 10(5), 181-192.

[12] Soberon-Chavez G., Aguirre-Ramírez M., Sánchez R., The Pseudomonas aeruginosa RhlA enzyme is involved in rhamnolipid and polyhydroxyalkanoate production. J. Ind. Microbiol. Biot., 2005, 32(11-12), 675.

[13] Pantazaki A.A., Papaneophytou C.P., Lambropoulou D.A., Simultaneous polyhydroxyalkanoates and rhamnolipids production by Thermus thermophilus HB8. AMB Express, 2011, 1(1), 17.

[14] Yadav A.K., Manna S., Pandiyan K., Singh A., Kumar M., Chakdar $\mathrm{H}$., et al., Isolation and characterization of biosurfactant producing Bacillus sp. from diesel fuel-contaminated site. Microbiology, 2016, 85(1), 56-62.

[15] Hashemi S.Z., Fooladi J., Ebrahimipour G., Khodayari S., Isolation and Identification of Crude Oil Degrading and Biosurfactant Producing Bacteria from the Oil-Contaminated Soils of Gachsaran. Appl. Food Biotechnol., 2016, 3(2), 83-89.
[16] Harley J.P., Prescott L.M., Laboratory exercises in microbiology. In: Cappuccino J.G., Sherman N., Microbiology. A laboratory manual. Pearson Education, McGraw-Hill, 2014.

[17] Satpute S., Bhawsar B., Dhakephalkar P., Chopade B., Assessment of different screening methods for selecting biosurfactant producing marine bacteria. Indian J. Mar. Sci., 2008. 37(3), 243-250.

[18] Walter V., Syldatk C., Hausmann R., Screening concepts for the isolation of biosurfactant producing microorganisms. In: Sen R., Biosurfactants. Springer, 2010, 1-13.

[19] Abu-Ruwaida A., Banat I., Haditirto S., Salem A., Kadri M., Isolation of biosurfactant-producing bacteria, product characterization, and evaluation. Eng. Life Sci., 1991, 11(4), 315-324.

[20] Hassanshahian M., Isolation and characterization of biosurfactant producing bacteria from Persian Gulf (Bushehr provenance). Mar. Pollut. Bull., 2014, 86(1-2), 361-366.

[21] Jain D., Collins-Thompson D., Lee H., Trevors J., A drop-collapsing test for screening surfactant-producing microorganisms. J. Microbiol. Meth., 1991, 13(4), 271-279.

[22] Burd G., Ward O.P., Bacterial degradation of polycyclic aromatic hydrocarbons on agar plates: the role of biosurfactants. Biotechnol. Tech., 1996, 10(5), 371-374.

[23] Langille M.G., Zaneveld J., Caporaso J.G., McDonald D., Knights D., Reyes J.A., et al., Predictive functional profiling of microbial communities using 16S rRNA marker gene sequences. Nat. Biotechnol., 2013, 31(9), 814-821.

[24] McCarthy C., Chromas: version 2.0. Technelysium PTY, Australia, 1996, 1(1), 39.

[25] Huang X., Madan A., CAP3: A DNA sequence assembly program. Genome Res., 1999, 9(9), 868-877.

[26] Dumontier M., Hogue C.W., NBLAST: a cluster variant of BLAST for NxN comparisons. BMC Bioinformatics, 2002, 3(1), 1-4.

[27] Kumar S., Nei M., Dudley J., Tamura K., MEGA: a biologistcentric software for evolutionary analysis of DNA and protein sequences. Brief. Bioinform., 2008, 9(4), 299-306.

[28] Banat I.M., Satpute S.K., Cameotra S.S., Patil R., Nyayanit N.V., Cost effective technologies and renewable substrates for biosurfactants' production. Front. Microbiol., 2014, $5,697$.

[29] Robert M., Mercade M., Bosch M., Parra J., Espuny M., Manresa M., et al., Effect of the carbon source on biosurfactant production by Pseudomonas aeruginosa 44T1. Biotechnol. Lett., 1989, 11(12), 871-874.

[30] Van Doan T., Hoi L.T., Phong T.H., Recovery of Poly(3hydroxybutyrate) from Yangia sp. ND199 by Simple Digestion with sodium hypochlorite. Vietnam J. Sci. Technol., 2015, 53(6), 706-714.

[31] Sharma D., Saharan B.S., Chauhan N., Bansal A., Procha S., Production and Structural Characterization of Lactobacillus helveticus Derived Biosurfactant. Sci. World J., 2014, 14, 1-9. 
[32] Elshikh M., Moya-Ramírez I., Moens H., Roelants S., Soetaert W., Marchant R., et al., Rhamnolipids and lactonic sophorolipids: natural antimicrobial surfactants for oral hygiene. J. Appl. Microbiol., 2017, 123(5), 1111-1123.

[33] Akiyama M., Taima Y., Doi Y., Production of poly(3hydroxyalkanoates) by a bacterium of the genus Alcaligenes utilizing long-chain fatty acids. Appl. Microbiol. Biot., 1992. 37(6), 698-701.

[34] Kim G.J., Lee I.Y., Yoon S.C., Shin Y.C., Park Y.H., Enhanced yield and a high production of medium-chain-length poly (3-hydroxyalkanoates) in a two-step fed-batch cultivation of Pseudomonas putida by combined use of glucose and octanoate. Enzyme Microb. Tech., 1997, 20(7), 500-505.

[35] Mothes G., Schnorpfeil C., Ackermann J.U., Production of PHB from crude glycerol. Eng. Life Sci., 2007, 7(5), 475-479.

[36] Scanes C.G., Animal Attributes Exploited by Humans (Nonfood Uses of Animals). In: Scanes C., Toukhsati S. (Eds.), Animals and Human Society. Elsevier, 2018, 13-40.

[37] Ashby R., Foglia T., Poly (hydroxyalkanoate) biosynthesis from triglyceride substrates. Appl. Microbiol. Biot., 1998, 49(4), 431-437.
[38] Pereira J.F., Gudiña E.J., Costa R., Vitorino R., Teixeira J.A., Coutinho J.A., et al., Optimization and characterization of biosurfactant production by Bacillus subtilis isolates towards microbial enhanced oil recovery applications. Fuel, 2013, 111, 259-268.

[39] Nitschke M., Costa S.G., Haddad R., Gonçalves G., Lireny A., Eberlin M.N., et al., Oil wastes as unconventional substrates for rhamnolipid biosurfactant production by Pseudomonas aeruginosa LBI. Biotechnol. Progr., 2005, 21(5), 1562-1566.

[40] Cortés-Camargo, S., Pérez-Rodríguez N., de Souza Oliveira R.P., Huerta B.E.B., Domínguez J.M., Production of biosurfactants from vine-trimming shoots using the halotolerant strain Bacillus tequilensis ZSB10. Ind. Crop. Prod., 2016, 79, 258-266.

[41] Domingos, D.F., de Faria A.F., de Souza Galaverna R., Eberlin M.N., Greenfield P., Zucchi T.D., et al., Genomic and chemical insights into biosurfactant production by the mangrove-derived strain Bacillus safensis CCMA-560. Appl. Microbiol. Biot., 2015, 99(7), 3155-3167.

[42] Al-Wahaibi Y., Al-Bahry S., Elshafie A., Al-Bemani A., Joshi S., Al-Bahri A., Screening of Minimal Salt Media for Biosurfactant Production by Bacillus spp. World Academy of Science, Engineering and Technology IJEEM, 2014, 8(2). 